\title{
Application of absolute principal component analysis to size distribution data: identification of particle origins
}

\author{
T. W. Chan ${ }^{1, *}$ and M. Mozurkewich ${ }^{1}$ \\ ${ }^{1}$ Department of Chemistry and Centre for Atmospheric Chemistry, York University, Toronto, Ontario, Canada \\ *now at: Environment Canada, Toronto, Ontario, Canada
}

Received: 15 August 2006 - Published in Atmos. Chem. Phys. Discuss.: 18 October 2006

Revised: 16 January 2007 - Accepted: 9 February 2007 - Published: 16 February 2007

\begin{abstract}
Absolute principal component analysis can be applied, with suitable modifications, to atmospheric aerosol size distribution measurements. This method quickly and conveniently reduces the dimensionality of a data set. The resulting representation of the data is much simpler, but preserves virtually all the information present in the original measurements. Here we demonstrate how to combine the simplified size distribution data with trace gas measurements and meteorological data to determine the origins of the measured particulate matter using absolute principal component analysis. We have applied the analysis to four different sets of field measurements that were conducted at three sites in southern Ontario. Several common factors were observed at all the sites; these were identified as photochemically produced secondary aerosol particles, regional pollutants (including accumulation mode aerosol particles), and trace gas variations associated with boundary layer dynamics. Each site also exhibited a factor associated specifically with that site: local industrial emissions in Hamilton (urban site), processed nucleation mode particles at Simcoe (polluted rural site), and transported fine particles at Egbert (downwind from Toronto).
\end{abstract}

\section{Introduction}

Atmospheric aerosol particles play an important role in climate and air quality issues. These particles are either emitted into or formed in the atmosphere and then undergo substantial modification due to coagulation and gas-to-particle conversion (nucleation and condensation). There is a need to better understand both the origins of atmospheric particles and the processes that modify them.

Correspondence to: M. Mozurkewich

(mozurkew@yorku.ca)
Many receptor models have been developed for identifying sources of air pollutants and to estimate the source contributions. Among the tools that have been used for this are factor analysis, principal component analysis, and positive matrix factorization. These analyses have typically focused on particle composition (Qin and Oduyemi, 2003; Maenhaut et al., 2002; Manoli et al., 2002; Yu and Chang, 2002; Hien et al., 2001; Song et al., 2001; Artaxo et al., 1999) and gas concentration (Guo et al., 2004a, b; Blanchard et al., 2002; Ho et al., 2001) measurements since their basic assumptions would appear to be the most valid for these types of measurements. In some cases, such as in the studies by Swietlicki et al. (1996) and Paterson et al. (1999), the composition data is divided into coarse and fine particle fractions. Chan et al. (2000) extended this approach somewhat by applying Target Transformation Factor Analysis to particle composition data obtained with a six stage high volume cascade impactor.

To obtain more insights into particle origins, there have been several attempts to include some particle size information in these analyses. Both Ruuskanen et al. (2001) and Vallius et al. (2003) applied principal component analysis to $24 \mathrm{~h}$ averaged data sets that included number concentrations for ultrafine and accumulation mode particles, with the boundary set at $0.1 \mu \mathrm{m}$. Ruuskanen et al. only included a few other variables, such as blackness and mass of $\mathrm{PM}_{2.5}$, and obtained factors that associated these with either the ultrafine or accumulation mode particles. Vallius et al. included elemental composition, absorption data, and gas phase $\mathrm{NO}_{\mathrm{x}}$ and $\mathrm{SO}_{2}$ concentrations. Their results identified five different factors, including local traffic emissions, trans-boundary air pollutants, re-suspended soil dust, heavy oil combustion, and sea salt particles.

A few studies have applied factor analysis techniques to data sets that included detailed size distribution data. Wåhlin et al. (2001) applied factor analysis to such a data set that also included measurements of $\mathrm{CO}$ and $\mathrm{NO}_{\mathrm{x}}$. They identified three factors: one associated with long range transported

Published by Copernicus GmbH on behalf of the European Geosciences Union. 
secondary particles and the other two related to vehicle emissions. Kim et al. (2004) applied both positive matrix factorization and Unmix to a volume distribution data set measured in Seattle. They obtained four factors, identified as accumulation mode particles from wood burning, secondary accumulation mode aerosol particles, and two factors related to vehicle emissions. Zhou et al. (2004) applied positive matrix factorization to size distribution measurements and then compared the results with measurements of trace gases $\left(\mathrm{O}_{3}\right.$, $\left.\mathrm{NO}, \mathrm{NO}_{\mathrm{x}}, \mathrm{SO}_{2}, \mathrm{CO}\right)$, particulate mass $\left(\mathrm{PM}_{2.5}\right)$, sulfate, organic carbon, and elemental carbon. They identified five factors: secondary aerosol particles, diesel truck emissions, traffic aerosol, combustion (power station and biomass fires), and photochemically driven nucleation particles.

Most of these studies used either principal component analysis (PCA) (Miller et al., 2002; Harrison et al., 1996; Thurston and Spengler, 1985) or positive matrix factorization (PMF) (Hopke, 2003; Paatero, 1997; Paatero and Tapper, 1994). The major difference between the two techniques is that PCA does not have constraints on the values of either the component loadings or scores, but requires that the resulting components be orthogonal, while PMF requires component loadings and scores to be non-negative, but has no orthogonality requirement. The lack of a non-negativity requirement in PCA has the potential of giving physically unreasonable results in the form of negative values for quantities that must be non-negative. However, in practice this is not usually a problem since, after Varimax rotation, it is typical that for each component all scores (the amounts of the component present) that are not near zero have the same sign; these can be chosen to be positive. Thus, in practice it is possible to implement an effective non-negativity constraint for absolute PCA scores. The same can not be said for loadings (the relative amounts of each measured species in the component); however, it is not clear that a non-negativity constraint is always appropriate for loadings. For example, negative loadings might represent an anticorrelation between species. For these reasons, we believe that the non-negativity constraint of PMF is not a large advantage unless physically reasonable results can not be obtained with PCA.

Both PCA and PMF are capable of identifying different sources and their composition features without any prior knowledge about the sources. Huang et al. (1999) performed PMF and PCA on an aerosol composition data set and concluded that the two techniques can provide indistinguishable results. They also found that, to obtain meaningful results, the inclusion of appropriate input data and appropriate usage of the method are more important than the specific method used.

On the other hand, to gain freedom from the orthogonality condition PMF uses an iterative method to fit the component loadings and scores to the measurements. This makes PMF numerically more difficult to implement than PCA. Another advantage of PMF has been that it is designed to permit the weighting of data; however, as shown in the preceding paper
(Chan and Mozurkewich, 2007), it is also possible to apply approximate weights in PCA. In the present application, we find that there is no difficulty with negative scores in excess of noise. Negative loadings do occur, but these appear to represent physically meaningful anticorrelations in the data. Therefore, we prefer to take advantage of the relative simplicity of PCA.

In this paper, we apply principal component analysis to data sets from four field studies conducted in southern Ontario; these data sets include number size distributions, trace gas measurements, and meteorological data. The analysis is done in two steps. First we apply weighted absolute principal component analysis, as described in the preceding paper, to the measured aerosol size distribution measurements in order to reduce the data dimensionality. Each of the resulting components covers a limited range of particle sizes. In a sense, this resembles "binning" the data, but since the analysis uses the data to determine the bins, virtually all the information in the original data set is retained. In the second step, we combine these components with trace gas and meteorological data in a more conventional principal component analysis. The components resulting from this analysis are useful in identifying the origins of the particulate matter.

\section{Measurements}

The data sets used in this paper were obtained from four field studies that were conducted in southern Ontario: Egbert 2003; Hamilton 2000; Simcoe 2000; and Hamilton 1999. The locations of these sampling sites are shown in Fig. 1 and the latitudes, longitudes, and altitudes of the sites are given in Table 1 along with the start and end dates of the measurements. All size distribution measurements were measured with a DMA-CPC system over 5-min intervals with 16 size bins per decade resolution. Ambient particles were size selected with a TSI 3071 differential mobility analyser (DMA) operating in a fast scan mode (Wang and Flagan, 1990). Particles exiting the DMA were counted by either a TSI 3010 or a TSI 3025 condensation particle counter (CPC). Additonal details about the DMA setup are given by Mozurkewich et al. (2004). Information on the total number of size bins, measured particle size range, DMA sheath and aerosol flows, and CPC model type used in different field studies are summarized in Table 2.

The Egbert 2003 data was taken at the Meteorological Service of Canada's (MSC) Centre for Atmospheric Research Experiments at Egbert; a rural site that is located about $80 \mathrm{~km}$ north of Toronto, Ontario. This site is surrounded by crop land, with no major anthropogenic source nearby. Air that reaches this site from the south and southeast is expected to contain traffic pollutants, such as $\mathrm{NO}_{\mathrm{x}}$. On the other hand, air that comes from the north generally contains less anthropogenic pollutants, except when it has passed over Sudbury; 


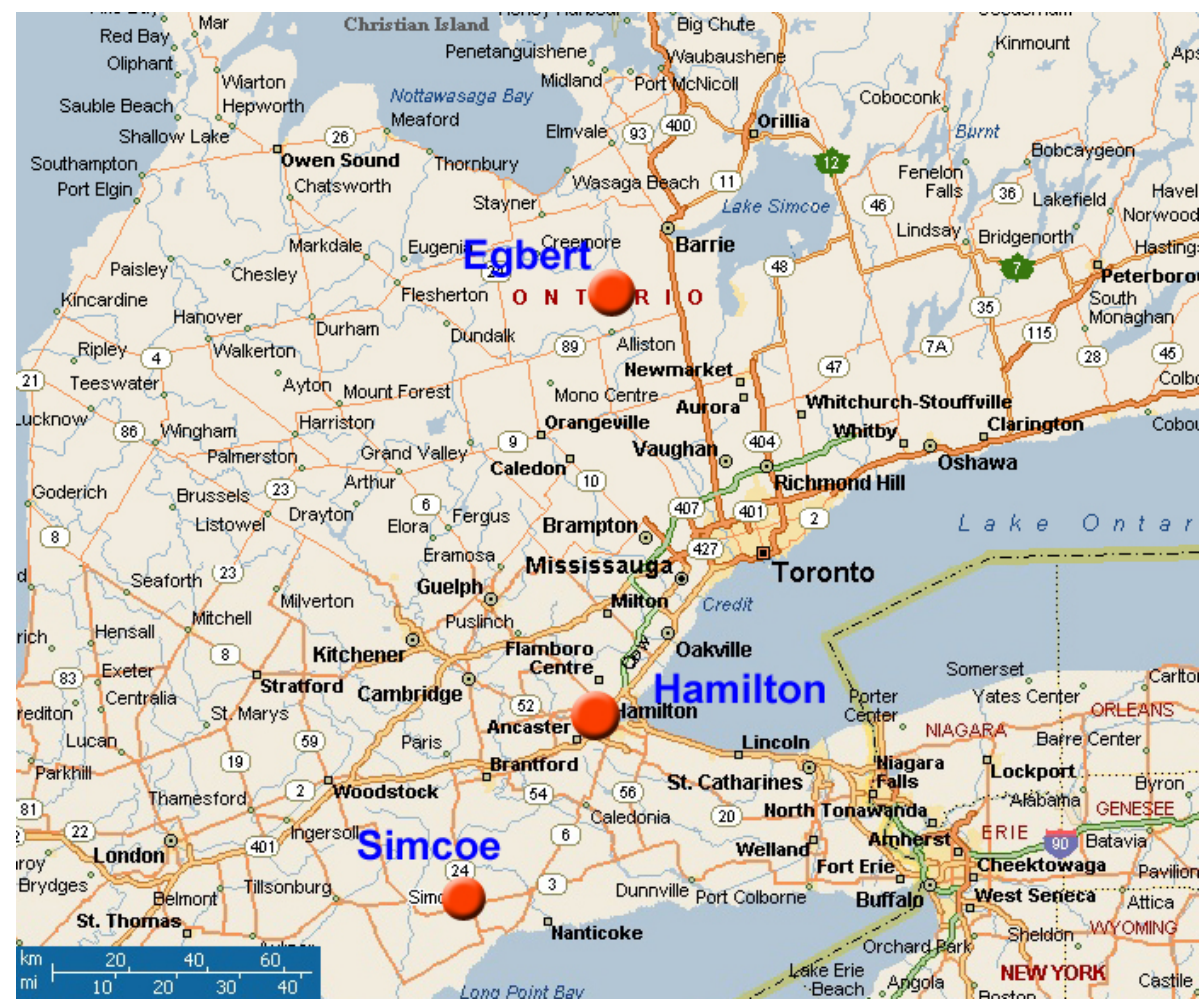

Fig. 1. Sampling sites for the Egbert 2003, Hamilton 2000, Simcoe 2000, and Hamilton 1999 field studies (map source: http://mappoint. msn.com).

Table 1. Locations and durations of the field studies.

\begin{tabular}{llllll}
\hline Field study & Latitude & Longitude & Altitude & Start date & End date \\
\hline Egbert 2003 & $44^{\circ} 12^{\prime} \mathrm{N}$ & $79^{\circ} 48^{\prime} \mathrm{W}$ & $251 \mathrm{~m}$ & 15 April 2003 16:41 & 8 May 2003 10:15 \\
Hamilton 2000 & $43^{\circ} 15^{\prime} \mathrm{N}$ & $79^{\circ} 51^{\prime} \mathrm{W}$ & $237 \mathrm{~m}$ & 23 June 2000 14:22 & 19 July 2000 11:17 \\
Simcoe 2000 & $42^{\circ} 50^{\prime} \mathrm{N}$ & $80^{\circ} 30^{\prime} \mathrm{W}$ & - & 1 July 2000 14:42 & 19 July 2000 10:43 \\
Hamilton 1999 & $43^{\circ} 15^{\prime} \mathrm{N}$ & $79^{\circ} 51^{\prime} \mathrm{W}$ & $237 \mathrm{~m}$ & 16 July 1999 15:06 & 28 July 1999 13:43 \\
\hline
\end{tabular}

then $\mathrm{SO}_{2}$ and $\mathrm{SO}_{4}^{2-}$ levels may be high. Meteorological and trace gas measurements were provided by MSC.

The Hamilton 2000 and Hamilton 1999 data sets were taken at Kelly station, an Ontario Ministry of the Environment (OME) monitoring site located in downtown Hamilton, Ontario. For Hamilton 1999, ambient air was measured by sampling from a $10 \mathrm{~cm}$ diameter glass manifold through which air was pumped from about a meter above the rooftop at a rate of $1.0 \mathrm{~m}^{3} \mathrm{~min}^{-1}$. For Hamilton 2000, the DMA-CPC system was set inside a plastic box, which was located on the rooftop of the station. Ambient air was sampled directly from outside of the box via a $6 \mathrm{~mm}$ stainless steel tube of about $70 \mathrm{~cm}$ in length with a downward pointed elbow at the end to avoid rain. The air at the Kelly station site is strongly affected by local traffic and industrial emissions. Meteorological and trace gas measurements were provided by OME.
The Simcoe 2000 data were taken at a rural OME site just outside of the small town of Simcoe, located about $70 \mathrm{~km}$ southwest of Hamilton. Air at the Simcoe site is usually not strongly affected by local sources, but pollution levels are generally high due to trans-boundary transport from the United States. Occasionally the Simcoe site is impacted by emissions from a steel mill, petroleum refinery, and a coalfired electricity generation station located to the southeast of the site, near Nanticoke. Meteorological and trace gas measurements were provided by Rotek Environmental.

For each field data set, we used the method described in the preceding paper and applied absolute principal component analysis to the entire 5-minute size distribution data sets for each study to obtain the rotated component loadings and their corresponding component scores; the shape of these rotated components are given in the preceding paper and their 
Table 2. Specifics of the DMA-CPC systems used in the field studies. Flows are in actual liters per minute, i.e. volumetric flow at ambient temperature and pressure.

\begin{tabular}{llllll}
\hline Data set & Bins & Size range & Sheath flow & Aerosol flow & CPC type \\
\hline Egbert 2003 & 30 & $9.3-640 \mathrm{~nm}$ & $5.0 \mathrm{alpm}$ & $1.0 \mathrm{alpm}$ & TSI 3010 \\
Hamilton 2000 & 28 & $7.0-294 \mathrm{~nm}$ & $11.0 \mathrm{alpm}$ & $1.0 \mathrm{alpm}$ & TSI 3025 \\
Simcoe 2000 & 33 & $11.9-466 \mathrm{~nm}$ & $5.4 \mathrm{alpm}$ & $1.0 \mathrm{alpm}$ & TSI 7610 \\
Hamilton 1999 & 28 & $6.0-294 \mathrm{~nm}$ & $11.0 \mathrm{alpm}$ & $1.0 \mathrm{alpm}$ & TSI 3025 \\
\hline
\end{tabular}

Table 3. Input data used in the mixed data sets. The number of "points" is the number of one hour averages used in each data set. The component diameters are the maxima of the aerosol component loadings.

\begin{tabular}{lllll}
\hline Data set & Points & Component diameters $(\mathrm{nm})$ & Trace gases & Other data \\
\hline Egbert 2003 & 519 & $9,19,38,64,113,228,384$ & $\mathrm{NO}_{\mathrm{y}}, \mathrm{SO}_{2}$ & Solar radiation \\
Hamilton 2000 & 594 & $21,45,85,171$ & $\mathrm{NO}_{\mathrm{x}}, \mathrm{SO}_{2}, \mathrm{O}_{\mathrm{x}}, \mathrm{CO}$ & Wind speed \\
Simcoe 2000 & 318 & $12,17,29,52,87,143,232,359$ & $\mathrm{NO}_{\mathrm{x}}, \mathrm{SO}_{2}, \mathrm{O}_{\mathrm{x}}$ & Wind speed \\
Hamilton 1999 & 287 & $9,15,24,45,87,178$ & $\mathrm{NO}_{\mathrm{x}}, \mathrm{SO}_{2}, \mathrm{O}_{\mathrm{x}}, \mathrm{CO}$ & Wind speed \\
\hline
\end{tabular}

peak diameters are given in Table 3 . The absolute component scores obtained from each field study data set were then converted to hourly averages and used as input data for the analyses reported here. This was done because the trace gas measurements were available as hourly averages. The averaging was done according to the measurement times for the trace gas measurements and meteorological data. The total number of hourly averaged points, the available gas measurements, and other meteorological data are summarized in Table 3.

\section{Methodology}

\subsection{Assembly of the mixed data set}

The first step of the analysis is to assemble a mixed data set containing the size distributions, the gas measurements, and meteorological data. The size distribution data used here are the rotated aerosol component scores obtained as described in the preceding paper. These replace the 28 to 33 size bins with four to eight monomodal components, depending on the complexity of the data set. We found that qualitatively similar results can be obtained using various number of aerosol components; the results reported here included the maximum number of aerosol components (that is, all "mixed" components) in order to avoid discarding features that occur only occasionally in the data. An exception was made in the case of the Hamilton 2000 data, where we used four aerosol components instead of the maximum of five. This is because the nucleation mode was absent from the Hamilton 2000 data and the four component fit gave loadings that were very similar to the four Aitken and accumulation mode components observed during Hamilton 1999. We decided that by using these we would be better able to compare the results of the two studies.

The mixed data set also includes measurements of $\mathrm{CO}$, $\mathrm{NO}_{\mathrm{x}}\left(\mathrm{NO}+\mathrm{NO}_{2}\right), \mathrm{SO}_{2}, \mathrm{O}_{\mathrm{x}}\left(\mathrm{NO}_{2}+\mathrm{O}_{3}\right)$, wind speed, and ground level solar radiation (when available). $\mathrm{NO}_{\mathrm{x}}$ and $\mathrm{O}_{\mathrm{x}}$ are used because the rapid photochemical interconversion between $\mathrm{NO}, \mathrm{NO}_{2}$, and $\mathrm{O}_{3}$ results in only two of these species being independent. For the Egbert 2003 data set, $\mathrm{NO}_{\mathrm{y}}$ (the sum of $\mathrm{NO}_{\mathrm{x}}, \mathrm{N}_{2} \mathrm{O}_{5}, \mathrm{HNO}_{3}, \mathrm{HONO}$, organic nitrates, and organic peroxy nitrates) is used instead of $\mathrm{NO}_{\mathrm{x}}$ because the later information was not available.

\subsection{Scaling the mixed data set}

In the preceding paper (Chan and Mozurkewich, 2007), we emphasized the importance of weighting the data set prior to the principal component analysis; this is because some data are known to be more reliable than others and measurement uncertainty can contribute significantly to the variance. On the other hand, if the input data are weighted inappropriately, results might be misleading because of over- or underestimation of particular portions of the data. In the mixed data sets, the various measurements were obtained from independent systems. For the most part, instrument noise did not contribute significantly to the data variance. As a result, it may not be appropriate to assign measurement-based weights in the same manner as used for the size distribution data. When we attempted to do this, we obtained unsatisfactory results. Therefore we decided to scale the data using the standard method such that all columns have unit variances; this causes all variables to contribute equally in the analysis. The scaling was done by dividing individual columns in the mixed data set by the corresponding standard deviations. An optimal weighting scheme might lie somewhere between 

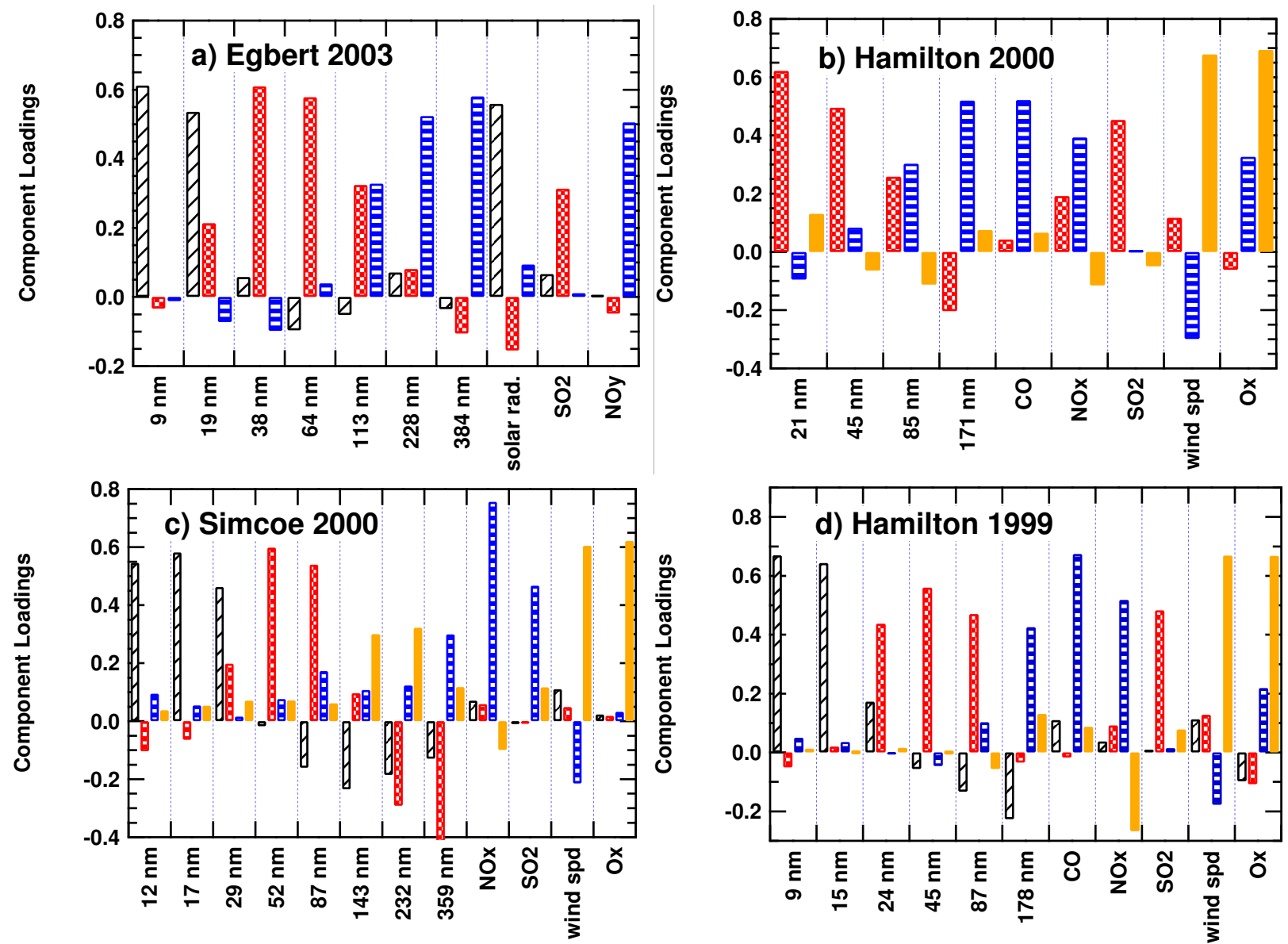

Fig. 2. The important factors identified for the different field studies: photochemical nucleation (black, striped); regional pollution (blue, horizontal bars); boundary layer dynamics (solid yellow); site specific (red, cross-hatched). (a) Egbert 2003, site specific source is transported fine particles. (b) Hamilton 2000, site specific source is local emission. (c) Simcoe 2000, site specific source is processed nucleation. (d) Hamilton 1999, site specific source is local emission.

this extreme and the extreme of purely measurement-based weighting; at present, such a scheme is not available. Because a different type of scaling was required for the auxiliary data than for the size distribution data, the principal component analysis was carried out in two steps. First, a weighted analysis was applied to the size distribution data as described in the preceding paper. Then the resulting scores were used in assembling the mixed data set used as input to a second principal component analysis.

\subsection{Principal component analysis}

Principal component analysis was applied to the scaled mixed data set. Varimax rotation was applied to the retained factor loadings and these were fit to the measurements to generate a set of factor scores. Deciding the number of factors to retain for each data set is a critical issue. Retaining too few factors results in combining different sources, while retaining too many factors splits sources among factors in a physically unreasonable manner. We found that the results obtained from the modified scree plots (defined in the preceding paper) were difficult to interpret since there were only slight breaks in the slopes; however, these did provide a good starting point for deciding the number of factors to retain. In each case, we carried through the analysis with the number of retained factors obtained from the scree plot and also with both one more and one fewer factor retained. The results were examined to determine if they provided a reasonable physical interpretation. In each case, we found that one set of results was much more reasonable than the others. This sometimes resulted in keeping either one more factor or one less than implied by the modified scree plot. 


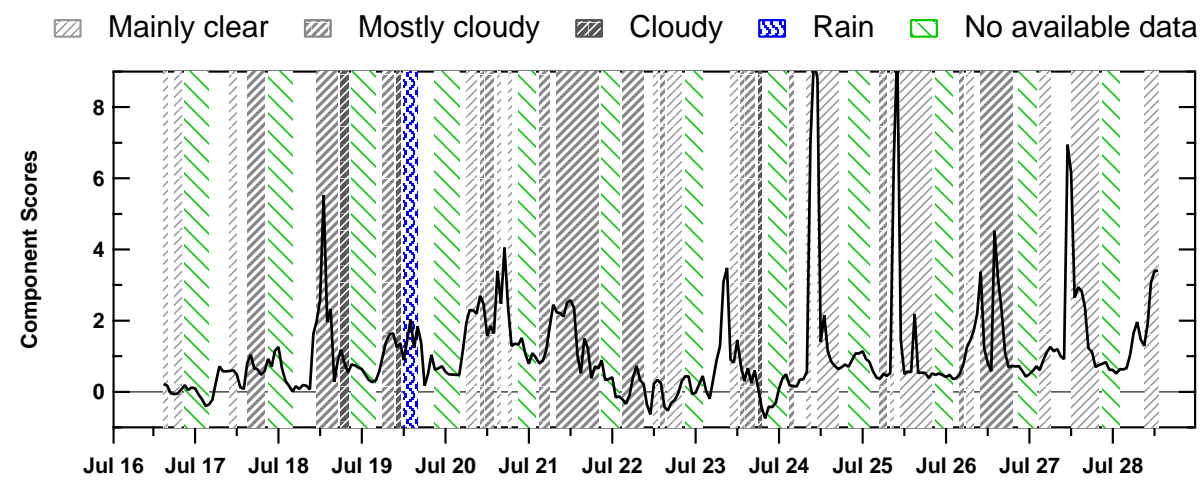

Fig. 3. Variations of the photochemical process factor scores obtained from the Hamilton 1999 field study. The major tick marks represent mid-night and the minor tick marks are noon. The intervals with no data are at night. The shaded areas represent different degrees of cloud coverage, obtained from Environment Canada. These hourly averaged data represent the fractional coverage of the sky by clouds, in tenths. There are four categories: clear ( 0 tenths), mainly clear (1-4 tenths), mostly cloudy (5-9 tenths), and cloudy (10 tenths). Heavy rain was observed during the afternoon of 19 July.

\section{Results and discussion}

\subsection{General description of data results}

Figure 2 shows the factor loadings for the four field studies. Because of the data scaling used, both the loadings and scores are dimensionless. The aerosol components, obtained from applying PCA to the size distributions, are labeled by their peak diameters. Each of the factors is assigned a name based on the loadings associated with that factor and the time series of the scores; these are described in the following sections. Note that these factors include some non-material variables such as wind speed and solar radiation. A technique such as PCA does not directly identify sources; it only identifies groups of correlated variables. The identification of a factor (or a portion of a factor) as being due to a source is a matter of providing an interpretation of the correlations.

In the following sections we discuss each of the factors observed and give our reasons for identifying them as we do. Several factors appear at multiple sites, with very similar loadings in each case. For example, the component labelled "regional pollution" (Sect. 4.3) appears in all four studies. The component labeled "photochemical nucleation" (Sect. 4.2) appears in all cases except Hamilton 2000 and the one labelled "boundary layer dynamics" (Sect. 4.4) appears in all but the Egbert 2003 data. In addition, each site appears to have a site specific factor (Sects. 4.5 through 4.7) largely loaded on the Aitken mode particles.

\subsection{Photochemically driven nucleation}

In all the data sets except Hamilton 2000, we observe a factor, shown in Figs. 2a, c, and d, that has high positive loadings on nucleation mode particles and small negative loadings on accumulation mode particles. This factor shows almost no correlations with other gas phase measurements. In the Eg- bert 2003 data set (Fig. 2a), this factor also shows a strong correlation with ground level solar radiation. For the other data sets, we do not have solar radiation measurements; but Fig. 3 shows the variations of the absolute scores for this factor along with the degree of cloud coverage for Hamilton 1999. The factor scores always peak during the day with the increase being especially strong on sunny and mostly clear days; this indicates that the production of the nucleation mode particles is photochemically driven. Occasional double peaks were observed, such as on 19, 20, 21, and 26 July. The interruption of the production of nucleation mode particles appears to be caused by on and off cloud coverage. Based on these observations, we identify this as a photochemical process factor, representing the nucleation of secondary aerosol particles in the atmosphere.

The photochemical process factor does not appear in the Hamilton 2000 data set (Fig. 2b). The weather in Hamilton was unusually cloudy and rainy during that study; as a result, significant concentrations of nucleation mode particles were not observed. The average size distributions measured in Hamilton in 1999 and 2000 are shown in Fig. 4; the average size distributions for particles larger than $80 \mathrm{~nm}$ diameter are virtually identical, but the nucleation mode was absent in 2000.

Although the nucleation is likely driven by the oxidation of $\mathrm{SO}_{2}$ (Birmili et al., 2000), this species does not appear as a significant part of this factor. This is not too surprising since variations in solar radiation can drive large variations in the nucleation rate even if there is no change in $\mathrm{SO}_{2}$. Also, as pointed out by Kulmala et al. (2004), the presence of preexisting particles slows down the particle nucleation rate due to coagulational scavenging of small nuclei and by lowering the non-volatile vapor concentration $\left(\mathrm{H}_{2} \mathrm{SO}_{4}\right.$ in this case). As a result, variations in the $\mathrm{H}_{2} \mathrm{SO}_{4}$ concentration, and therefore the nucleation rate, can be largely independent of the variations in the $\mathrm{SO}_{2}$ concentration; this leads to a poor correlation 


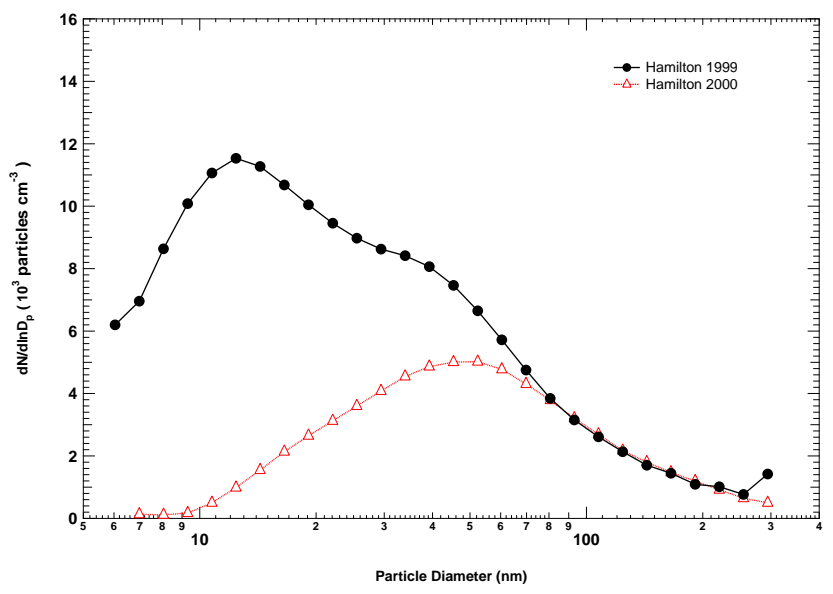

Fig. 4. Average size distributions for Hamilton 1999 and Hamilton 2000 .

between $\mathrm{SO}_{2}$ and nucleation. Consistent with the scavenging effect, the photochemical process factors in Fig. 2 all show small negative loadings on the accumulation mode particles.

The photochemical nucleation particles factor found by Zhou et al. (2004) showed similar features as ours: it consisted of mainly $3 \mathrm{~nm}$ particles, peaked at mid to late afternoon, and showed no correlations with any trace gas measurements. Our observations of the correlation between the photochemical process component and ground level solar radiation is consistent with the findings of Birmili and Wiedensohler (2000), Boy and Kulmala (2002), Shi et al. (2001), and Mozurkewich et al. (2004), all of whom observed an association of nucleation and UV radiation.

\subsection{Regional pollutants}

As shown in Fig. 2, the data sets have a common factor that has high positive loadings on accumulation mode particles, $\mathrm{CO}$, and $\mathrm{NO}_{\mathrm{x}}$ together with a small negative loading on wind speed. For the measurements taken at the Hamilton site, there is also a positive loading on $\mathrm{O}_{\mathrm{x}}$. As shown in Fig. 5, the scores for this factor are very similar at the Hamilton and Simcoe sites in 2000 and are much less variable than those of the local emission (see Sect. 4.4) or photochemical process factors. Because of this, we identify this factor as regional pollution.

Figure 2c shows a large positive loading for $\mathrm{SO}_{2}$ at the Simcoe site; this is not observed at the other sites. The result at Simcoe is more in line with what might be expected. The absence of $\mathrm{SO}_{2}$ from the regional pollution factors at the Hamilton and Egbert sites is a consequence of high $\mathrm{SO}_{2}$ levels associated with strong local sources (see Sects. 4.5 and 4.6) and the scaling used. The scaling causes each variable to have the same variance. At Hamilton and Egbert, the variation in regional $\mathrm{SO}_{2}$ is small compared to variation due to the local emissions; as a result, the scaling suppresses the

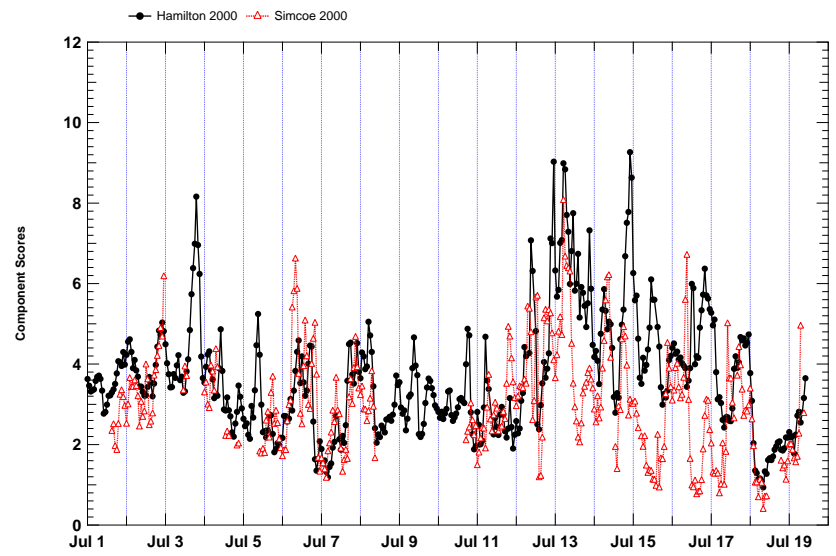

Fig. 5. Variation of the regional pollution factor scores at the Hamilton and Simcoe sites during field study in 2000. The figure shows only the 18 days when measurements were available at both sites.

$\mathrm{SO}_{2}$ "signal" in the regional pollution component. At Simcoe, there is some variation in $\mathrm{SO}_{2}$ due to local sources to the southeast of the site. However, these were sampled so infrequently during this study that they contributed minimally to the overall variance. As a result, the variation in $\mathrm{SO}_{2}$ associated with the regional pollution is more readily observed.

In Fig. 5, significant deviations between the regional pollution scores for Hamilton and Simcoe occur during the period from mid-day on 13 July to early morning on 17 July. During this period, the two sets of scores show overall decreasing trends, but the scores were generally higher in Hamilton than in Simcoe. These deviations appear to be associated with the difference in local wind direction at the two sites. For instance, from 14 July 20:00 to 16 July 00:00, the local wind at the Simcoe site was primarily from NW, whereas the local wind at the Hamilton site was from N to NE; a similar situation was also observed from 16 July 12:00 to 16 July 21:00. At other times, the local wind directions at the two sites were very consistent.

In the Egbert 2003 data, we observed a different pattern; at times, the regional pollution component scores were very low. A histogram of the scores is bimodal; the medium values in the two modes are 0.7 and 3.5 with a minimum at an absolute score value of 2.5; this was chosen as the boundary between two groups of values. The conditional probability function, CPF, was used to investigate the wind direction dependence of these two groups. CPF estimates the probability that a given source contribution from a given wind direction will exceed a predetermined threshold criterion (Kim et al., 2004; Kim and Hopke, 2004; Zhou et al., 2004; Ashbaugh et al., 1985). The CPF is defined as

$\mathrm{CPF}=f \times \frac{m_{\Delta \theta}}{n_{\Delta \theta}}$

where $m_{\Delta \theta}$ is the number of occurrences in the direction sector $\theta$ to $\theta+\Delta \theta$ that exceed a certain predetermined threshold 


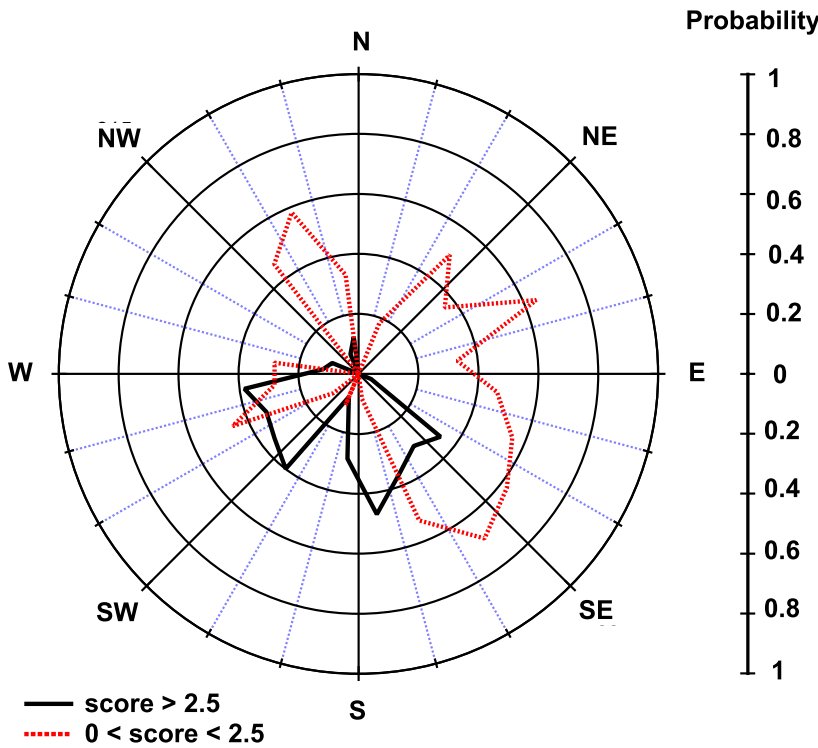

Fig. 6. Conditional probability function plots for the atmospheric regional pollutants at Egbert. The red dotted curve indicates wind directions for which this factor makes a minor contribution, while the black solid curve indicates wind directions for which this factor makes a major contribution.

and $n_{\Delta \theta}$ is the total number of occurrences within the sector. In our case, $\Delta \theta$ is defined as 15 degrees. The weighting factor, $f$, is incorporated to avoid misleading results from sectors with only a few data points; if $n_{\Delta \theta} \geq 10, f=1$ and if $n_{\Delta \theta}<10$,

$f=\sqrt{n_{\Delta \theta}} / \sqrt{10}$.

Figure 6 shows the conditional probability functions for scores below and above 2.5. It is clear that high scores for this component are associated with winds from the SE through SW (Toronto and the United States). Low scores are associated with winds from the NW to NE; this is consistent with the fact that those are forested areas with no major anthropogenic sources.

\subsection{Boundary layer dynamics}

All data sets except Egbert 2003 (Figs. 2b, c, and d) have a factor that shows high positive loadings on $\mathrm{O}_{\mathrm{x}}$ and wind speed, a small negative loading on $\mathrm{NO}_{\mathrm{x}}$, and a small positive loading on the accumulation mode particles. The time series of the scores show a strong diurnal variation with maxima near noon and minima in the early mornings. This is consistent with the build up of $\mathrm{NO}_{\mathrm{x}}$ and the depletion of $\mathrm{O}_{\mathrm{x}}$ under the nocturnal inversion layer. During the morning, as the boundary layer grows, air within the inversion layer mixes with the air mass above the inversion layer, which contains higher $\mathrm{O}_{\mathrm{x}}$ and lower $\mathrm{NO}_{\mathrm{x}}$. The positive correlation of wind speed with $\mathrm{O}_{\mathrm{x}}$ is due to the fact that the ground level wind speed is higher during the daytime. These results are consistent with the findings from Swietlicki et al. (1996), who observed a strong anti-correlation between $\mathrm{NO}_{2}$ and $\mathrm{O}_{3}$.

\subsection{Local anthropogenic emission at Hamilton}

The Hamilton 2000 (Fig. 2b) and Hamilton 1999 (Fig. 2d) mixed data sets have a common factor that does not appear in the other data sets. This factor, which we identify as local anthropogenic emissions, shows high loadings on the Aitken mode particles and $\mathrm{SO}_{2}$, small positive loadings on $\mathrm{NO}_{\mathrm{x}}$ and wind speed, and a small negative loading on $\mathrm{O}_{\mathrm{x}}$. The wind direction dependence of the component scores is shown in Fig. 7; clearly, high values of the scores are associated with wind directions between $45^{\circ} \mathrm{E}$ and $90^{\circ} \mathrm{E}$. In Fig. 7, the plot is superimposed on a street map of the city of Hamilton with the center of the plot at the location of the measurement site. The result strongly implies that this component is from the two steel mills in Hamilton. The Aitken particles and $\mathrm{SO}_{2}$ are probably the by-products of the coke making process (Environment Canada, 2001).

\subsection{Processed nucleation mode particles at Simcoe}

The Simcoe 2003 data (Fig. 2c) contain a factor that has a high positive loading on Aitken particles and small negative loadings on the nucleation mode and accumulation mode particles. Similar to the photochemical process factor, this factor has no correlation with any trace gas measurements or meteorological data. Figure 8 shows the time series of the scores for this factor and the photochemical process factor for this site; a lag between the two can be clearly seen after most of the nucleation events $(5,6,7,11,12$, and 17 July). Review of the corresponding size distributions clearly shows that the observed Aitken mode particles (represented by the processed nucleation mode component) are not transported from other sources but grew from the freshly nucleated particles through condensation and coagulation. The lag between the two scores observed in Fig. 8 represents the finite time that is needed for the nucleation mode particles to grow to Aitken mode particle size ranges. Therefore, we identify this factor as processed nucleation mode particles; it represents the growth of the freshly nucleated particles into the Aitken particle size range. The negative loading on the nucleation mode particles represents the fact that the concentration of those particles decrease as they grow into to Aitken mode size range. The negative loadings on the accumulation mode particles probably occurs for the same reasons as in the photochemical process factor.

\subsection{Transported fine particles at Egbert}

The Egbert 2003 data (Fig. 2a) show a factor that has positive loadings on $\mathrm{SO}_{2}$ and Aitken particles and small negative loadings on the accumulation mode particles and solar radiation; this factor is similar to the local anthropogenic emission 


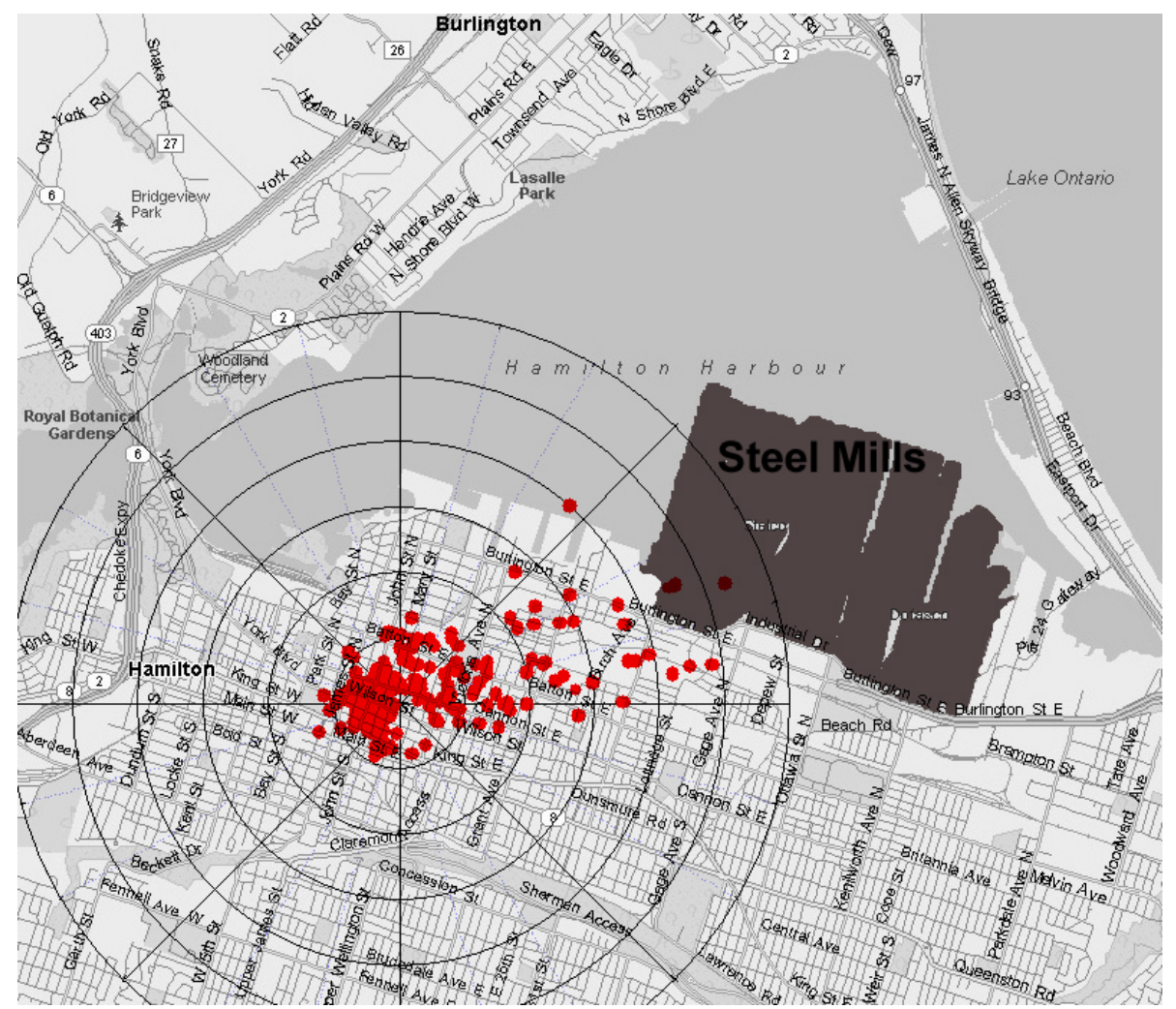

Fig. 7. Polar plot for the local anthropogenic emission factor scores (1999 data) superimposed on a street map of the city Hamilton (map source: http://mappoint.msn.com). Each radial increment represents the relative magnitude of the absolute factor scores. The measuring site is represented by the center of the polar plot. The dark grey area indicates the two large steel mills in Hamilton.

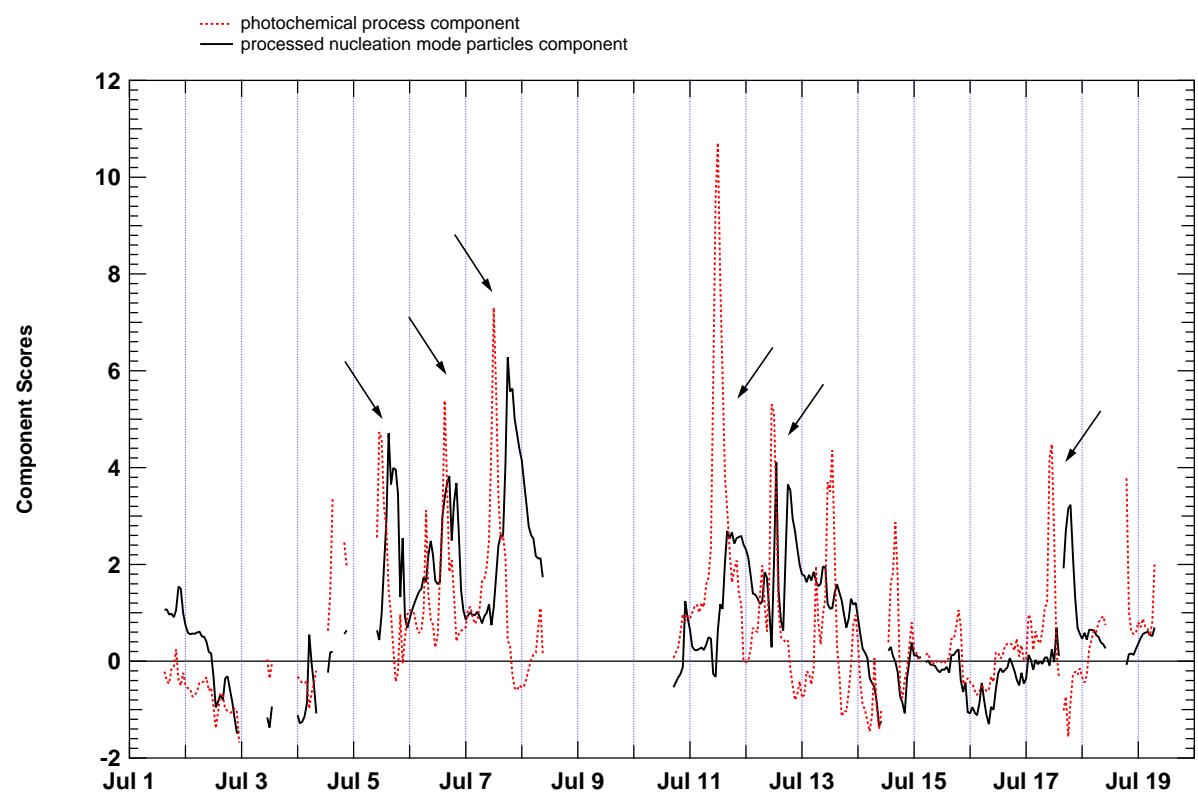

Fig. 8. Time series of the scores for the photochemical process factor (red dotted curve) and the processed nucleation mode particle factor (black solid) at Simcoe in 2003. 
factor that was identified at the Hamilton site, except that the particle sizes in this case are slightly larger. The conditional probability functions show that the major source for this factor is the Toronto area with a lesser contribution from the west (possibly from the area of Detroit in the United States). There is almost no contribution from the much cleaner areas to the north and east. Based on these observations, we identify this factor as transported fine particles. The most likely source is vehicle emissions, although there may also be some contribution from industrial emissions. This factor has a small negative loading on solar radiation; this is due to a steady increase in the scores during the daytime and a gradual decrease at night. It is not clear if this is associated with photochemistry or with boundary layer and transport dynamics.

\section{Conclusions}

Absolute principal component analysis was used to identify possible sources and origins of the measured ambient particulate matter from four different size distribution data sets measured at various locations in southern Ontario. The consistent results among different field measurements show that when combining particle number concentrations with different trace gas measurements and meteorological data, absolute principal component analysis can be useful in providing physical meaningful factors for interpretation.

Among the data sets, we identified three common factors that were observed at all the sites. The photochemical nucleation factor represents the nucleation of the secondary aerosol particles due to the presence of solar radiation and anthropogenic emissions. The ubiquity of this factor, even in areas with high particle loadings, is somewhat surprising. The atmospheric regional pollution factor consists of regional pollutants that have widespread sources (accumulation mode particles, $\mathrm{NO}_{\mathrm{x}}$, and $\mathrm{CO}$ ); this factor is distinctly lower at the Egbert site when the air flow is from relatively clean areas to the north and east. $\mathrm{SO}_{2}$ was also present in this factor at Simcoe; its contribution to this factor at Hamilton and Egbert appears to have been masked by the large local variability in $\mathrm{SO}_{2}$ at those sites. The boundary layer dynamics factor represents variations of $\mathrm{NO}_{\mathrm{x}}$ and $\mathrm{O}_{\mathrm{x}}$ associated with formation and break up of the nocturnal inversion layer.

In addition, there were three factors that were each unique to one of the three sites. The local anthropogenic emission factor identified at Hamilton represents the Aitken particles and $\mathrm{SO}_{2}$ emitted from two local steel mills. At Simcoe, we observed a factor which we refer to as the processed nucleation mode particles; this results from the growth of particles following nucleation events. The Egbert site was impacted by a factor that consists of Aitken particles and $\mathrm{SO}_{2}$ that is likely to be mostly vehicle emissions transported from the Toronto area and the United States.
In summary, this study shows that principal component analysis can be effectively applied to data sets including size distribution data to provide useful information on the sources and origins of measured particulate matter. Some of the factors provided by the analysis are consistently observed at the three different sampling sites while others are unique to each site.

Acknowledgements. We thank R. Leaitch and J. O'Brien of the Meteorological Service of Canada for use of the solar radiation and meteorological data from the Center for Atmospheric Research Experiments (CARE) Egbert monitoring site. Funding for this research was provided by the Natural Science and Engineering Research Council of Canada and by the Canadian Foundation for Climate and Atmospheric Sciences.

Edited by: C. George

\section{References}

Artaxo, P., Oyola, P., and Martinez, R.: Aerosol composition and source apportionment in Santiago de Chile, Nucl. Instrum. Methods Phys. Res., Sect. B, 150, 409-416, 1999.

Ashbaugh, L. L., Malm, W. C., and Sadeh, W. Z.: A residence time probability analysis of sulfur concentrations at Grand Canyon National Park, Atmos. Environ., 19, 1263-1270, 1985.

Birmili, W. and Wiedensohler, A.: New particle formation in the continental boundary layer: meteorological and gas phase parameter influence, Geophys. Res. Lett., 27, 3325-3328, 2000.

Birmili, W., Wiedensohler, A., Plass-Dulmer, C., and Berresheim, H.: Evolution of newly formed aerosol particles in the continental boundary layer: a case study including $\mathrm{OH}$ and $\mathrm{H}_{2} \mathrm{SO}_{4}$ measurements, Geophys. Res. Lett., 27, 2205-2208, 2000.

Blanchard, P., Froude, F. A., Martin, J. B., Dryfhout-Clark, H., and Woods, J. T.: Four years of continuous total gaseous mercury (TGM) measurements at sites in Ontario, Canada, Atmos. Environ., 36, 3735-3743, 2002.

Boy, M. and Kulmala, M.: Nucleation events in the continental boundary layer: influence of physical and meterological parameters, Atmos. Chem. Phys., 2, 1-16, 2002,

http://www.atmos-chem-phys.net/2/1/2002/.

Chan, Y. C., Vowles, P. D., McTainsh, G. H., Simpson, R. W., Cohen, D. D., Bailey, G. M., and McOrist, G. D.: Characterisation and source identification of $\mathrm{PM}_{10}$ aerosol samples collected with a high volume cascade impactor in Brisbane (Australia), Sci. Total Environ., 262, 5-19, 2000.

Chan, T. W. and Mozurkewich, M.: Simplified representation of atmospheric aerosol size distributions using absolute principal component analysis, Atmos. Chem. Phys., 7, 875-886, 2007, http://www.atmos-chem-phys.net/7/875/2007/.

Environment Canada: Environmental Code of practice for integrated steel mills - CEPA 1999 code of practice, 1st edition, EPS 1/MM/7 (http://www.ec.gc.ca/nopp/docs/cp/1mm7/en/toc. cfm), 2001.

Guo, H., Wang, T., and Louie, P. K. K.: Source apportionment of ambient non-methane hydrocarbons in Hong Kong: application of a principal component analysis/absolute principal component scores (PCA/APCS) receptor model, Environ. Pollut., 129, 489498, 2004a. 
Guo, H., Wang, T., Simpson, I. J., Blake, D. R., Yu, X. M., Kwok, Y. H., and Li. Y. S.: Source contributions to ambient VOCs and CO at a rural site in eastern China, Atmos. Environ., 38, 4551-4560, 2004b.

Harrison, R. M., Smith, D. J. T., and Luhana, L.: Source apportionment of atmospheric polycyclic aromatic hydrocarbons collected from an urban location in Birmingham, UK, Environ. Sci. Technol., 30, 825-832, 1996.

Hien, P. D., Binh, N. T.,Truong, Y., Ngo, N. T., and Sieu, L. N.: Comparative receptor modeling study of TSP, $\mathrm{PM}_{2}$ and $\mathrm{PM}_{2-10}$ in Ho Chi Minh City, Atmos. Environ., 35, 2669-2678, 2001.

Ho, K. F., Lee, S. C., and Chiu, G. M. Y.: Characterization of selected volatile organic compounds, polycyclic aromatic hydrocarbons and carbonyl compounds at a roadside monitoring station, Atmos. Environ., 36, 57-65, 2001.

Hopke, P. K.: Recent developments in receptor modeling, J. Chemom., 17, 255-265, 2003.

Huang, S., Rahn, K. A., and Arimoto, R.: Testing and optimizing two factor-analysis techniques on aerosol at Narragansett, Rhode Island, Atmos. Environ., 33, 2169-2185, 1999.

Kim, E. and Hopke, P. K.: Comparison between conditional probability function and nonparametric regression for fine particle source directions, Atmos. Environ., 38, 4667-4673, 2004.

Kim, E., Hopke, P. K., Larson, T. V., and Covert, D. S.: Analysis of ambient particle size distributions using Unmix and positive matrix factorization, Environ. Sci. Technol., 38, 202-209, 2004.

Kulmala, M., Vehkamäki, H., Petäjä, T., Dal Maso, M., Lauri, A., Kerminen, V. M., Birmili, W., and McMurry, P. H.: Formation and growth rates of ultrafine atmospheric particles: a review of observations, J. Aerosol Sci., 35, 143-176, 2004.

Maenhaut, W., Fernández-Jiménez M. T., Rajta, I., and Artaxo, P.: Two-year study of atmospheric aerosols in Alta Floresta, Brazil: multielemental composition and source apportionment, Nucl. Instrum. Methods Phys. Res., Sect. B, 189, 243-248, 2002.

Manoli, E., Voutsa, D., and Samara, C.: Chemical characterization and source identification/apportionment of fine and coarse air particles in Thessaloniki, Greece, Atmos. Environ., 36, 949961, 2002

Miller, S. L., Anderson, M. J., Daly, E. P., and Milford, J. B.: Source apportionment of exposures to volatile organic compounds. I. Evaluation of receptor models using simulated exposure data, Atmos. Environ., 36, 3629-3641, 2002.

Mozurkewich, M., Chan, T. W., Aklilu, Y. A., and Verheggen, B.: Aerosol particle size distributions in the lower Fraser Valley: evidence for particle nucleation and growth, Atmos. Chem. Phys., 4, 1047-1062, 2004, http://www.atmos-chem-phys.net/4/1047/2004/.
Paatero, P.: Least squares formation of robust non-negative factor analysis, Chemom. Intell. Lab. Syst., 37, 23-35, 1997.

Paatero, P. and Tapper, U.: Positive matrix factorization: a nonnegative factor model with optimal utilization of error estimates of data values, Environmetrics, 5, 111-126, 1994.

Paterson, K. G., Sagady, J. L., Hooper, D. L., Bertman, S. B., Carroll, M. A., and Shepson, P. B.: Analysis of air quality data using positive matrix factorization, Environ. Sci. Technol., 33, 635641, 1999.

Qin, Y. and Oduyemi, K.: Atmospheric aerosol source identification and estimates of source contributions to air pollution in Dundee, UK, Atmos. Environ., 37, 1799-1809, 2003.

Ruuskanen, J., Tuch, Th., Ten Brink, H., Peters, A., Khlystov, A., Mirme, A., Kos, G. P. A., Brunekreef, B., Wichmann, H. E., Buzorius, G., Vallius, M., Kreyling, W. G., and Pekkanen, J.: Concentration of ultrafine, fine and $\mathrm{PM}_{2.5}$ particles in three European cities, Atmos. Environ., 35, 3729-3738, 2001.

Shi, J. P., Evan, D. E., Khan, A. A., and Harrison, R. M.: Sources and concentration of nanoparticles $(<10 \mathrm{~nm}$ diameter $)$ in the urban atmosphere, Atmos. Environ., 35, 1193-1202, 2001.

Song, X. H., Polissar, A. V., and Hopke, P. K.: Sources of fine particle composition in the northeastern U.S., Atmos. Environ., 35, 5277-5286, 2001.

Swietlicki, E., Puri, S., Hansson, H. C., and Edner, H.: Urban air pollution source apportionment using a combination of aerosol and gas monitoring techniques, Atmos. Environ., 30, 2795-2809, 1996.

Thurston, G. D. and Spengler, J. D.: A quantitative assessment of source contributions to inhalable particulate matter pollution in metropolitan Boston, Atmos. Environ., 19, 9-25, 1985.

Vallius, M., Lanki, T., Tiittanen, P., Koistinen, K., Ruuskanen, J., and Pekkanen, J.: Source apportionment of urban ambient $\mathrm{PM}_{2.5}$ in two successive measurement campaigns in Helsinki, Finland, Atmos. Environ., 37, 615-623, 2003.

Wåhlin, P., Palmgren, F., and Van Dingenen, R.: Experimental studies of ultrafine particles in streets and the relationship to traffic, Atmos. Environ., 35 (S1), S63-S69, 2001.

Wang, S. C. and Flagan, R. C.: Scanning Electrical Mobility Spectrometer, Aerosol Sci. Technol., 13, 230-240, 1990.

Yu, T. Y. and Chang, L. F. W.: Delineation of air-quality basins utilizing multivariate statistical methods in Taiwan, Atmos. Environ., 35, 3155-3166, 2002.

Zhou, L., Kim, E., Hopke, P. K., Stanier, C. O., and Pandis, S.: Advanced factor analysis on Pittsburgh particle size-distribution data, Aerosol Sci. Technol., 38(S1), 118-132, 2004. 